\title{
CARTA DOS EDITORES CONVIDADOS
}

\section{História da saúde: visível, audível e consequente ${ }^{1}$}

Há 22 anos, em comemoração ao $125^{\circ}$ aniversário da American Public Health Association, os historiadores Elizabeth Fee e Theodore M. Brown assinaram um editorial para o American Journal of Public Health ressaltando alguns aspectos que, segundo eles, sinalizavam para a importância da história nas análises sobre saúde. O texto afirma que a pesquisa histórica, entre outras potencialidades, possibilitaria, a partir da apreciação de iniciativas passadas, a avaliação de ações contemporâneas no campo da saúde. Indica que a história se mostra especialmente útil para a identificação de padrões, continuidades e descontinuidades no âmbito das ideias e ações da saúde. Concluindo, os autores afirmam que "a história pode fornecer novos insights sobre as dificuldades de mudança, sejam em realidades sociais e políticas, atitudes ou comportamentos" (Fee, Brown, 1997, p.1763).

Mais recentemente, em meados de 2014, a questão da importância e utilidade da história da medicina (leia-se história da saúde, para a historiografia brasileira), já amplamente aceita, voltou à tona em uma controvérsia sobre os caminhos desse campo historiográfico. De um lado, Richard Horton (2014) afirmou, em um artigo na prestigiosa revista The Lancet, que a maioria dos historiadores da medicina havia abandonado as pretensões de conectar as questões do passado às do presente, buscando transformá-las em ferramentas de resistência às mudanças perversas que o mercado impinge à medicina de nossa época. Por isso, diferentemente dos pioneiros, como François Delaport, John Farley, Roy Porter e outros, os historiadores da atualidade seriam invisíveis, inaudíveis e, como resultado, inconsequentes.

O historiador da medicina Carsten Timmermann (4 ago. 2014) se incumbiu de, rapidamente, responder ao artigo. No blog Somatosphere, escreveu um texto mostrando-se consternado com as observações do colega e afirmando que bastava olhar para sua estante para comprovar que essa afirmativa era falsa. Em uma visada, podia ver obras como a de Jeremy Greene, Ilana Lowy, Robert Aronowitz e outros que, a partir de estudos sobre a história, convidam o leitor a refletir sobre o presente. Tal característica mostrava como os

\footnotetext{
${ }^{1}$ Nota do editor científico: Nos últimos anos, a história da saúde no Brasil e na América Latina se converteu em um complexo e rico campo de pesquisa e reflexão. É, além disso, uma história fundamental para defender a importância de sociedades com sistemas robustos de saúde pública. Sem dúvida, os historiadores da Casa de Oswaldo Cruz e o periódico História, Ciências, Saúde - Manguinhos têm cumprido um papel relevante nessa importante área de estudos. Por isso, convidamos um editor adjunto da revista para apresentar um breve panorama da trajetória e relevância da história da saúde. Carlos Henrique Assunção Paiva faz uma reflexão, mais pertinente do que nunca, em um momento de desmoronamento da saúde pública brasileira.
} 
historiadores da medicina contemporâneos não poderiam ser avaliados de forma tão adversa. Apesar de recusar a pecha atribuída aos historiadores por seu colega, Timmermann termina seu texto exortando os historiadores da medicina a sair de sua zona de conforto com mais frequência e conversar com cientistas e médicos, bem como com outras audiências. Tal iniciativa, além de sua importância social, certamente levaria à ampliação da audiência dos historiadores.

Levando em consideração a perspectiva de Fee e Brow, e sua ampliação ou renovação por Timmermann, podemos dizer que a história da saúde brasileira, diante da vigência de um sistema único de saúde, tem à frente objetivos e possibilidades ainda mais desafiadores e amplos. Para além de uma atividade que buscaria a compreensão e a avaliação de iniciativas e contextos no campo da saúde, uma renovada história teria como horizonte, também, a produção de subsídios ou orientações para as práticas profissionais a partir da compreensão de dinâmicas políticas, culturais e profissionais.

Quatro aspectos, em nossa leitura, compõem tal perspectiva. Primeiro, a história da saúde nos permite ter uma noção contextual dos problemas da população brasileira e da estrutura sanitária; ambos, socialmente determinados, são resultados de contingências históricas específicas, devendo, portanto, ser compreendidos à luz das demandas e dos constrangimentos de toda ordem. Em segundo lugar, a história da saúde nos fornece elementos para fazer uma análise crítica que discuta as práticas dos profissionais de saúde não somente como atos técnicos, mas como ações orientadas por visões políticas, ideológicas, culturais, mas também pessoais e morais. Em terceiro, a história da saúde nos dá a dimensão temporal das políticas de saúde que falam sobre seu tempo, sobre a sociedade brasileira, suas características e seus desafios. E, em quarto lugar, mas não menos importante, a história, a partir de seus contingentes de atores, potencializa a criação e o reforço de identidades institucionais.

Nessa perspectiva, portanto, a história da saúde pode ultrapassar os limites de um conhecimento puramente erudito ou abstrato, ela pode ser uma ferramenta analítica para a formulação e implementação de políticas públicas e para a construção e/ou o aperfeiçoamento de estratégias políticas e gerenciais adotadas. Pode também contribuir para que os diferentes profissionais, em suas ações diárias no âmbito dos serviços de saúde, reavaliem condutas e práticas já cristalizadas como hábitos na rotina dos serviços.

A operacionalização da história como ferramenta, entretanto, demanda uma reflexão sobre a formação dos historiadores e historiadoras da saúde, principalmente no que diz respeito à sua aproximação de discussões, conceitos, referenciais e métodos do próprio campo da saúde. De modo análogo ao apelo de Thomas Kuhn (2011, p.151-156) para que os historiadores da ciência conhecessem a lógica própria de seus objetos, é necessária à pesquisa em história da saúde uma compreensão das pautas colocadas hoje pelo próprio campo da saúde, de modo a aproximar as reflexões feitas pelos historiadores das preocupações de profissionais, gestores, pesquisadores em saúde e dos próprios usuários. Tal esforço também pode ser um mecanismo para demarcar um lugar específico à história da saúde nesse espaço de fronteira entre uma historiografia mais geral e o campo da saúde.

Conhecer os percursos no tempo dessa nossa complexa experiência social da saúde, das concepções e normas, das políticas e práticas que com elas se conectam, é tarefa essencial dos 
historiadores da saúde, de várias origens disciplinares. História, Ciências, Saúde - Manguinhos é um veículo exemplar dessa produção, assim como outras publicações da história, da saúde coletiva e das ciências sociais. E assim espera-se que permaneçam. De forma semelhante, o Observatório História e Saúde da Casa de Oswaldo Cruz vem atuando na pesquisa de temas relacionados aos problemas de saúde que hoje mais afetam a população brasileira. ${ }^{2}$

\section{REFERÊNCIAS}

FEE, Elizabeth; BROWN, Theodore.

Editorial: Why history? American Journal of Public Health, v.87, n.11, p.1763-1764. 1997.

HORTON, Richard.

The moribund body of medical history. The Lancet, v.384, n.9940. Disponível em: <https://doi. org/10.1016/S0140-6736(14)61050-3 >. Acesso em: 21 jan. 2020. 2014.

KUHN, Thomas.

As relações entre história e história da ciência. In: Kuhn, Thomas. A tensão essencial: estudos selecionados sobre tradição e mudança científica. São Paulo: Editora Unesp. p.145-179. 2011.

TIMMERMANN, Carsten.

Not moribund at all! An historian of medicine's response to Richard Horton. Somatosphere: Science, Medicine, and Anthropology. Disponível em: <http://somatosphere.net/2014/not-moribund-at-all-anhistorian-of-medicines-response-to-richard-horton.html>. Acesso em: 21 jan. 2020. 4 ago. 2014.
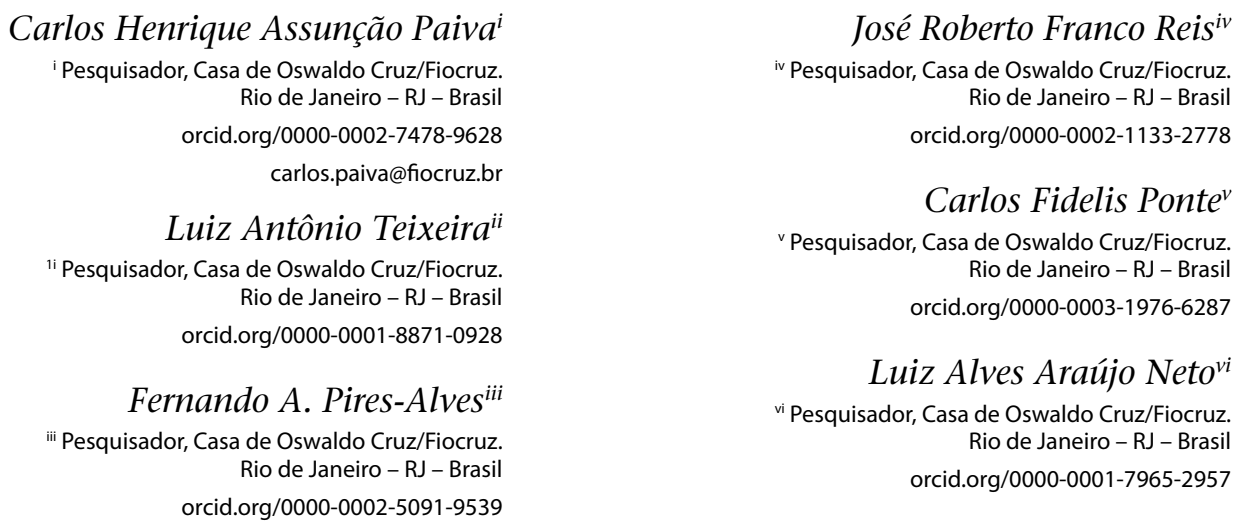

${ }^{2} \mathrm{O}$ texto teve colaboração de toda a equipe do Observatório, nominalmente: Carlos Henrique Assunção Paiva, Luiz Antônio Teixeira, Fernando A. Pires-Alves, José Roberto Franco Reis, Carlos Fidelis Ponte e Luiz Alves Araújo Neto. 


\section{ERR A TA}

Na "Carta do Editor Convidado" (http://dx.doi.org/10.1590/S0104-59702020000100001) publicada no v.27, n.1 de História, Ciências, Saúde - Manguinhos, considerem-se as seguintes correções:

- Na página 7, nota 1, onde se lia "Por isso, convidamos um editor adjunto da revista para apresentar um breve panorama da trajetória e relevância da história da saúde. Carlos Henrique Assunção Paiva faz uma reflexão, mais pertinente do que nunca, em um momento de desmoronamento da saúde pública brasileira.",

- leia-se "Por isso, convidamos o Observatório História e Saúde para apresentar um breve panorama da trajetória e relevância da história da saúde, mais pertinente do que nunca, em um momento de desmoronamento da saúde pública brasileira.".

- Na página 9, linha 5, onde se lia "brasileira. ${ }^{2 ",}$

- leia-se "brasileira.".

- Na página 9, linhas 19-23, onde se lia

"Carlos Henrique Assunção Paiva ${ }^{i}$

${ }^{i}$ Editor adjunto, pesquisador, Casa de Oswaldo Cruz/Fiocruz.

Rio de Janeiro - RJ - Brasil

orcid.org/0000-0002-7478-9628

carlos.paiva@fiocruz.br",

- leia-se

"Carlos Henrique Assunção Paiva ${ }^{\mathrm{i}}$

${ }^{i}$ Pesquisador, Casa de Oswaldo Cruz/Fiocruz.

Rio de Janeiro - RJ - Brasil

orcid.org/0000-0002-7478-9628

carlos.paiva@fiocruz.br

Luiz Antônio Teixeira ${ }^{\mathrm{ii}}$

ii Pesquisador, Casa de Oswaldo Cruz/Fiocruz.

Rio de Janeiro - RJ - Brasil

orcid.org/0000-0001-8871-0928 
Fernando A. Pires-Alves ${ }^{\mathrm{iii}}$

iii Pesquisador, Casa de Oswaldo Cruz/Fiocruz.

Rio de Janeiro - RJ - Brasil

orcid.org/0000-0002-5091-9539

José Roberto Franco Reis ${ }^{\text {iv }}$

iv Pesquisador, Casa de Oswaldo Cruz/Fiocruz.

Rio de Janeiro - RJ - Brasil

orcid.org/0000-0002-1133-2778

Carlos Fidelis Ponte ${ }^{\mathrm{v}}$

v Pesquisador, Casa de Oswaldo Cruz/Fiocruz.

Rio de Janeiro - RJ - Brasil

orcid.org/0000-0003-1976-6287

Luiz Alves Araújo Neto ${ }^{\mathrm{vi}}$

${ }^{v i}$ Pesquisador, Casa de Oswaldo Cruz/Fiocruz.

Rio de Janeiro - RJ - Brasil

orcid.org/0000-0001-7965-2957".

- Na página 9, suprima-se a nota 2 .

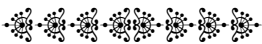

